\title{
Incidence Rates in Low-Grade Primary Brain Tumors: Are There Differences Between Men and Women? A Systematic Review
}

\author{
Jonas Nilsson ${ }^{\mathrm{a}, \mathrm{b}, \mathrm{e}, \mathrm{f}}$, Georg Holgersson ${ }^{\mathrm{a}, \mathrm{c}}$, Tobias Carlsson ${ }^{\mathrm{c}}$, Roger Henriksson ${ }^{\mathrm{b}, \mathrm{d}}$, \\ Stefan Bergstrom ${ }^{\mathrm{a}, \mathrm{c}}$, Michael Bergqvist ${ }^{\mathrm{a}, \mathrm{b}, \mathrm{c}}$
}

\begin{abstract}
Background: Incidence rates of adult low-grade primary brain tumors have previously been widely analyzed nationwide across the world, and most of these studies include data on incidence rates in men and women separately. However, to our knowledge, no worldwide international comparison has been made on possible differences in incidence rates of low-grade brain tumors between men and women. The primary aim was to review the incidence rates between men and women in adult low-grade primary brain tumors.
\end{abstract}

Methods: We searched for published articles in internationally peer reviewed journals that were identified through a systematic search of PubMed. Because of difficulties in interpreting data, we excluded all studies only including patient data before the second edition of World Health Organization (WHO) histological classification system of brain tumors (1993). We also made an overall analysis to calculate incidence rates of low-grade brain tumors in men and women separately.

Results: A total of 14 studies from the United States and Europe were reviewed. Overall mean age-adjusted incidence rate in men was 1.07 per 100,000 compared to 1.70 per 100,000 in women. No significant difference was seen in age-adjusted incidence rate between genders (Mann-Whitney $\mathrm{U}$ test; $\mathrm{P}=0.8347)$. No significant trend of age-adjusted incidence rate was seen in male patients $(P=0.757)$ nor in women $(\mathrm{P}=0.354)$.

Conclusion: The results must be interpreted with caution and more large international studies are warranted and should be made in a standardized manner differing low-grade tumors from high-grade tu-

Manuscript accepted for publication June 10, 2016

${ }^{a}$ Center for Research \& Development, Uppsala University/County Council of Gavleborg, Gavle Hospital, SE-801 87 Gavle, Sweden

${ }^{b}$ Department of Radiation Sciences \& Oncology, Umea University Hospital, SE-901 87 Umea, Sweden

'Department of Oncology, Gavle Hospital, SE-801 87 Gavle, Sweden

dRegional Cancer Center Stockholm, Gotland, Sweden

eDepartment of Radiology, Gavle Hospiral, SE-801 87 Gavle, Sweden

${ }^{f}$ Corresponding Author: Jonas Nilsson, Department of Radiology, Gavle Hospital, SE-80187 Gavle, Sweden. Email: Jonas.Nilsson@regiongavleborg.se

doi: http://dx.doi.org/10.14740/wjon976w mors according to the WHO 2007 brain tumor classification system. Also future studies should always state the ICD-O histology coding to ease future interpretations.

Keywords: Incidence rate; Low-grade brain tumors; Gender; Difference

\section{Introduction}

Incidence rates of adult low-grade primary brain tumors have previously been widely analyzed nationwide across the world, and most of these studies include data on incidence rates in men and women separately [1-3]. However, to our knowledge, no worldwide international comparison has been made on possible differences in incidence rates of low-grade brain tumors between men and women.

Previous studies have shown contradictive data on differences in incidence rate between men and women in low-grade tumors. For example, the low-grade vestibular schwannoma has in some studies shown no significant difference in incidence rate between men and women [4], whilst other has reported differences in incidence rate according to age [5]. Also, differences in incidence rate within genders have been suggested among a study including four Nordic countries; however, interpretation of these results was limited because of differences in reporting and coding the diagnosis between the different countries [6].

Other low-grade tumors such as meningiomas have previously reported higher incidence rate in women compared to that of men $[1,7]$. The pathogenicity is under discussion, but studies have shown differences in both gene expression and chromosome abnormalities associated to patients' gender, which may explain parts of this puzzle [8].

\section{The 2007 World Health Organization (WHO) classification}

Tumors in the central nervous system are divided based on histopathological assessment as per 2007 WHO classification, using a four-point scale. Per definition, a brain tumor is an abnormal tissue within the cranium including the brain, cra- 


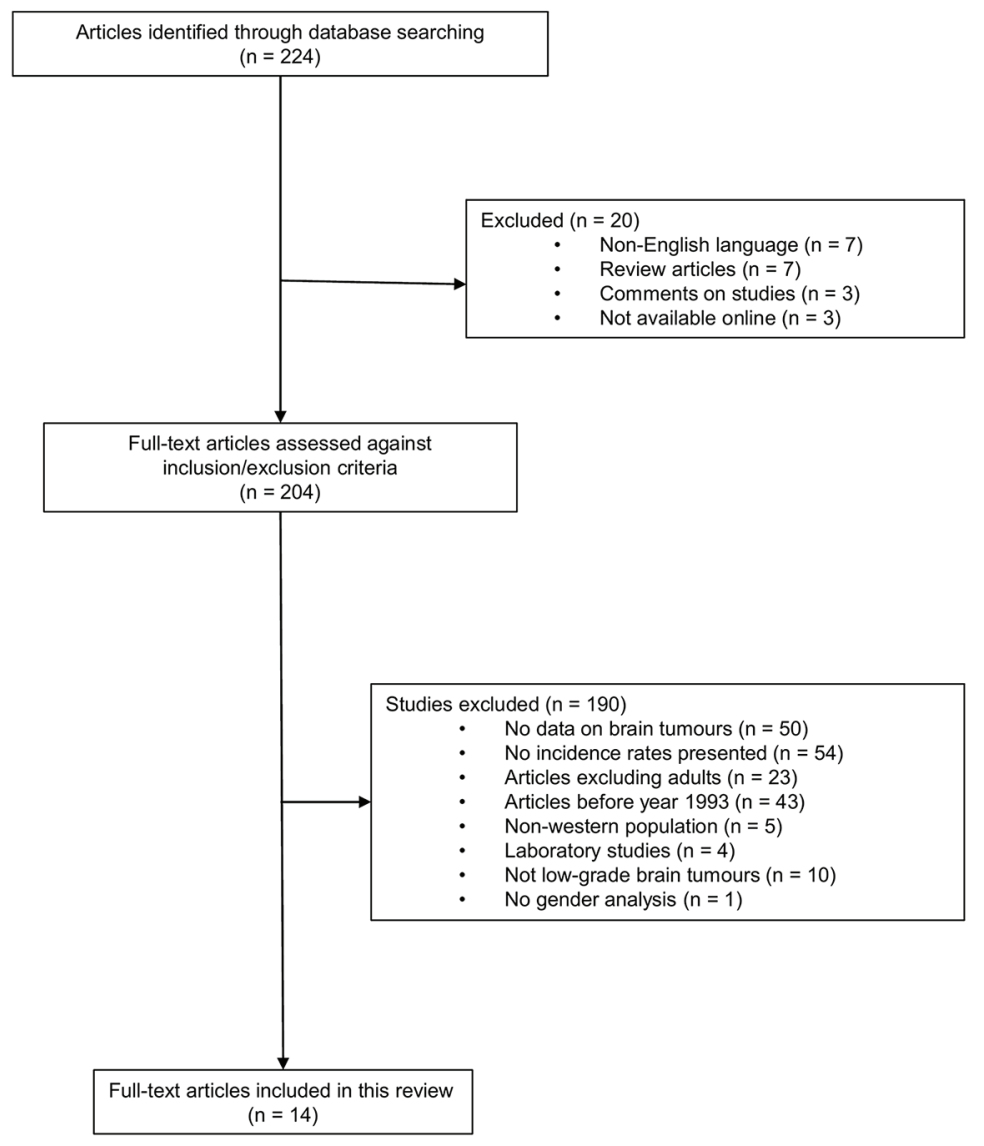

Figure 1. Article selection process.

nial nerves, meninges, skull, pituitary gland and pineal gland [9]. In the clinical setting, the grading system is an important tool to decide choice of therapy, particularly adjuvant radiation and chemotherapy. The scale ranges from grade I to grade $\mathrm{IV}$, describes the malignancy of the tumors and is used among the different histopathological groupings. Grade I describes tumors with low proliferation rate that may be curable with surgical resection only. Grade II tumors, on the other hand, are generally infiltrative and can transform to higher grades in the classification scale. Grade III tumors have even higher malignancy rates and are mostly treated with adjuvant radiotherapy or chemotherapy. Grade IV tumors are the most malignant in the scale, and include histological groupings of which a high mitotic activity and necrosis are often present. This is also associated with a poorer prognosis [10].

\section{Classification of tumors}

\section{International classification of diseases (ICD)}

The ICD classification system is a diagnostic tool made by the WHO aimed to classify diseases according to a systematic encoding system [11]. The ICD system has its roots back in the 19th century, and multiple updates of the system have been done since then. In 1975, the nineth revision (ICD-9) and in 1990 the 10th revision (ICD-10) were made [11, 12], and this system is used by most studies included in this review.

\section{International classification of diseases for oncology (ICD-O)}

The ICD-O is a system developed and revised by the WHO, used to systematically code tumors based on topography (anatomical site) and histology, and the third edition ICD-O-3 was revised in year 2000 [13].

\section{Systematic Nomenclature of Medicine (SNOMED)}

The histologic parts of ICD-O are incorporated into the SNOMED [13], which is a clinical terminology owned by the International Health Terminology Standards Development Organization (IHTSDO) [14].

\section{Registry systems}

The Central Brain Tumor Registry of the Unites States (CBTRUS) is an organization aimed to collect and provide epi- 
demiologic data on all benign and malignant primary brain tumors [15]. To gather data information, CBTRUS uses the Surveillance, Epidemiology, and End Results (SEER) program that was established in the United States (US) in 1973, with the aim to collect cancer statistic data from the US population [16]. CBTRUS also uses data from the National Program of Cancer Registries (NPCR) that collect data on cancer occurrence and initial treatments and, together with the SEER program, covers the entire US population [17].

Other countries normally use their respective national cancer registry in order to collect and provide information about cancer statistics in the population [18-22].

\section{Aim}

The primary aim was to review the incidence rates between men and women in adult low-grade primary brain tumors.

\section{Materials and Methods}

\section{Electronic database searches and article selection strategy}

We searched for published articles in internationally peer reviewed journals that were identified through a systematic search of PubMed. The mesh terms used were Brain Cancer Incidence Time Trends. Because of difficulties in interpreting data, we excluded all studies only including patient data before the second edition of WHO histological classification system of brain tumors (1993) [23]. We also excluded studies not written in the English language, studies not including data of primary brain tumors, review articles and articles excluding adult subjects.

\section{Data extraction}

For each selected article, the following data were extracted: histology, data source, study period (years), demography, number of subjects included, age interval, and average annual age-adjusted incidence rate by gender.

\section{Statistical methods}

The STATA 13 program was used for the analysis. Since the data did not have a normal distribution (Shapiro-Wilk W test, $\mathrm{P}$-value $<0.00001$ ), and since the variance of mean age-adjusted incidence rate differed between men and women (1.930 and 9.708, respectively), the Wilcoxon rank-sum (Mann-Whitney) test was used instead of a $t$-test to estimate differences in incidence rate between men and women.

For trend analysis, we compared the incidence rate within genders between time periods 1995 - 2004 and 2005 - 2010 by using the test for trend across ordered groups (nptrend). The incidence trend was analyzed in men and women separately. Different lengths in time periods were chosen because of very few numbers of studies before year 2005 .

\section{Results}

\section{Search results}

A total of 224 articles were found during the search. Exclusions were made because of the following reasons: seven were not written in English, 23 did not include adult patients only, 54 did not include information about incidence rate, 10 did not analyze low-grade brain tumors only, 50 did not study brain cancer, four were laboratory studies, seven were review articles, one did not analyze genders separately, three were excluded due to no online access, 43 only published data before 1993, five studied incidence rates based on non-Western population and three were comments on other articles (Supplementary 1, www. wjon.org). The remaining 14 articles did include incidence data on low-grade brain tumors, and were included in our analysis (Fig. 1). Eleven of these were based on US population, one article was published on four Nordic countries (Sweden, Finland, Denmark and Norway), one included Finnish population only, and one was based on Croatian data (Table 1 [1, 2, 5, 24-34]).

Since the studies analyzing the low-grade tumor pineocytoma made an overall calculation including pinealoma, NOS (ICD-O code 9630) and pineoblastoma (ICD-O code 9362), which is a highly malignant tumor (WHO grade IV), these data were not included in our analysis $[1,2]$.

\section{Results of the incidence rate analysis}

Overall mean value in age-adjusted incidence rate in men was $1.07(\mathrm{SD} \pm 1.389)$ per 100,000 compared to $1.70(\mathrm{SD} \pm 3.116)$ per 100,000 in women. However, because of differences in variance between genders, the Wilcoxon rank-sum (MannWhitney test) was used to calculate median differences. No significant difference was seen in age-adjusted incidence rate between genders $(\mathrm{P}=0.8347)$. Also, no significant trend of age-adjusted incidence rate was seen in male patients $(\mathrm{P}=$ $0.757)$ nor in women $(\mathrm{P}=0.354)$.

\section{Incidence rates and gender differences among the studies included}

\section{Tumors of the cranial and paraspinal nerves}

A total of seven studies analyzed age-adjusted incidence rate in tumors of the cranial and paraspinal nerves. Of these, six articles were based on US register data and one study showed results based on Croatian register data.

Three studies reported results on primary nerve sheath tumors, NOS, whereas three articles presented results on vestibular schwannomas and one study differed between the two histopathologic groupings and presented results separately. The incidence rate across all studies ranged from 0.3 to 1.7 per 
Table 1. Demography and Data Sources

\begin{tabular}{|c|c|c|c|c|}
\hline Author & Article & Demography & $\begin{array}{l}\text { Age interval } \\
\text { (years) }\end{array}$ & Data source \\
\hline Kshettry et al [5] & Incidence of vestibular schwannomas in the United States. & USA & All & CBTRUS \\
\hline Gittleman et al [29] & $\begin{array}{l}\text { Trends in central nervous system tumor incidence } \\
\text { relative to other common cancers in adults, adolescents, } \\
\text { and children in the United States, } 2000 \text { to } 2010 .\end{array}$ & USA & NA & CBTRUS \\
\hline Gabriel et al [28] & $\begin{array}{l}\text { Adult brain cancer in the US black population: a } \\
\text { Surveillance, Epidemiology, and End Results (SEER) } \\
\text { analysis of incidence, survival, and trends. }\end{array}$ & USA & $15-80+$ & SEER \\
\hline Gittleman et al [30] & $\begin{array}{l}\text { Descriptive epidemiology of pituitary tumors } \\
\text { in the United States, } 2004-2009 .\end{array}$ & USA & All & CBTRUS \\
\hline Ostrom et al [1] & $\begin{array}{l}\text { CBTRUS statistical report: primary brain and central nervous } \\
\text { system tumors diagnosed in the United States in } 2006-2010 \text {. }\end{array}$ & USA & All & CBTRUS \\
\hline Dolecek et al [2] & $\begin{array}{l}\text { CBTRUS statistical report: primary brain and central nervous } \\
\text { system tumors diagnosed in the United States in } 2005-2009 \text {. }\end{array}$ & USA & All & CBTRUS \\
\hline Kohler et al [24] & $\begin{array}{l}\text { Annual report to the nation on the status of cancer, } 1975 \text { - } \\
2007 \text {, featuring tumors of the brain and other nervous system. }\end{array}$ & USA & All & SEER and NPCR \\
\hline Raappana et al [32] & $\begin{array}{l}\text { Incidence of pituitary adenomas in } \\
\text { Northern Finland in } 1992-2007 .\end{array}$ & Finland & All & OUH data \\
\hline McCarthy et al [33] & $\begin{array}{l}\text { Time trends in oligodendroglial and } \\
\text { astrocytic tumor incidence. }\end{array}$ & USA & All & CBTRUS \\
\hline Deorah et al [34] & $\begin{array}{l}\text { Trends in brain cancer incidence and survival in } \\
\text { the United States: Surveillance, Epidemiology, } \\
\text { and End Results Program, } 1973 \text { to } 2001 .\end{array}$ & USA & All & SEER \\
\hline $\begin{array}{l}\text { Dobec-Meic } \\
\text { et al }[25]\end{array}$ & $\begin{array}{l}\text { Intracranial tumors in adult population of the } \\
\text { Varazdin County (Croatia) } 1996 \text { - 2004: a } \\
\text { population-based retrospective incidence study. }\end{array}$ & Croatia & $\geq 18$ & $\begin{array}{l}\text { Retrospective } \\
\text { multicenter } \\
\text { database search }\end{array}$ \\
\hline
\end{tabular}

100,000 population in men and 0.55 to 1.71 per 100,000 population in women between years 1985 and 2010 [1, 2, 5, 24-27].

\section{Low-grade astrocytic tumors}

Nine studies presented results of low-grade astrocytic tumors; however, only five showed data on age-adjusted incidence rate (Table 2 [1, 2, 5, 24-34]). One study analyzed data on astrocytic tumors, NOS among US black population and showed incidence rates of 0.80 per 100,000 in men compared to 0.60 per 100,000 in women during the period $1973-2008$ (Tables 2 and 3 [1, 2, 5, 24-34]). When analyzing the period of $1998-2008$, the average male incidence decreased to 0.31 per 100,000 compared to the female incidence of 0.18 per 100,000 , which was stated as a "sizable difference". No incidence rate ratio (IRR) was calculated, nor any statistical power in the differences between the genders [28].
Among the remaining four studies, three were based on US patients using CBTRUS registries, and one showed data based on Croatian population. The incidence rate of pilocytic astrocytoma was reported in the three American studies, ranging from 0.14 to 0.33 per 100,000 in men and 0.13 to 0.33 per 100,000 in women between years 2004 and 2010. Incidence rates of diffuse astrocytoma were presented by two US studies, ranging from 0.66 to 0.68 per 100,000 in men compared to 0.48 to 0.5 per 100,000 in women between years 2005 and 2010 .

\section{Oligodendroglial tumors}

Six studies analyzed oligodendroglial tumors; however, only three reported incidence rate data. Two of these were based on US population, and one study was made using data on Croatian patients. The incidence rate ranged from 0 to 0.30 per 100,000 in men and 0.24 to 0.4 per 100,000 in women between years 
Table 2. Incidence Rates by Histology

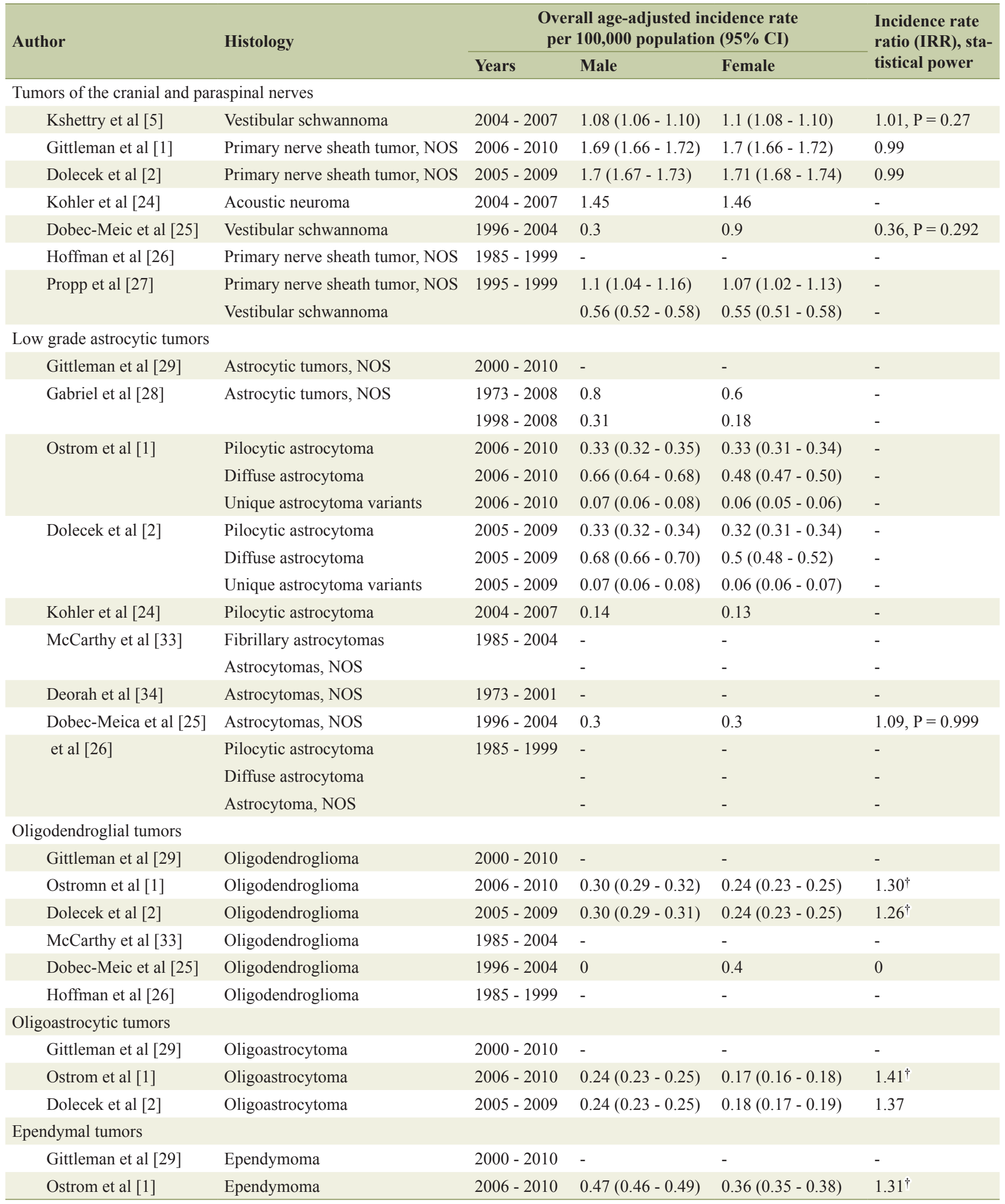


Table 2. Incidence Rates by Histology - (continued)

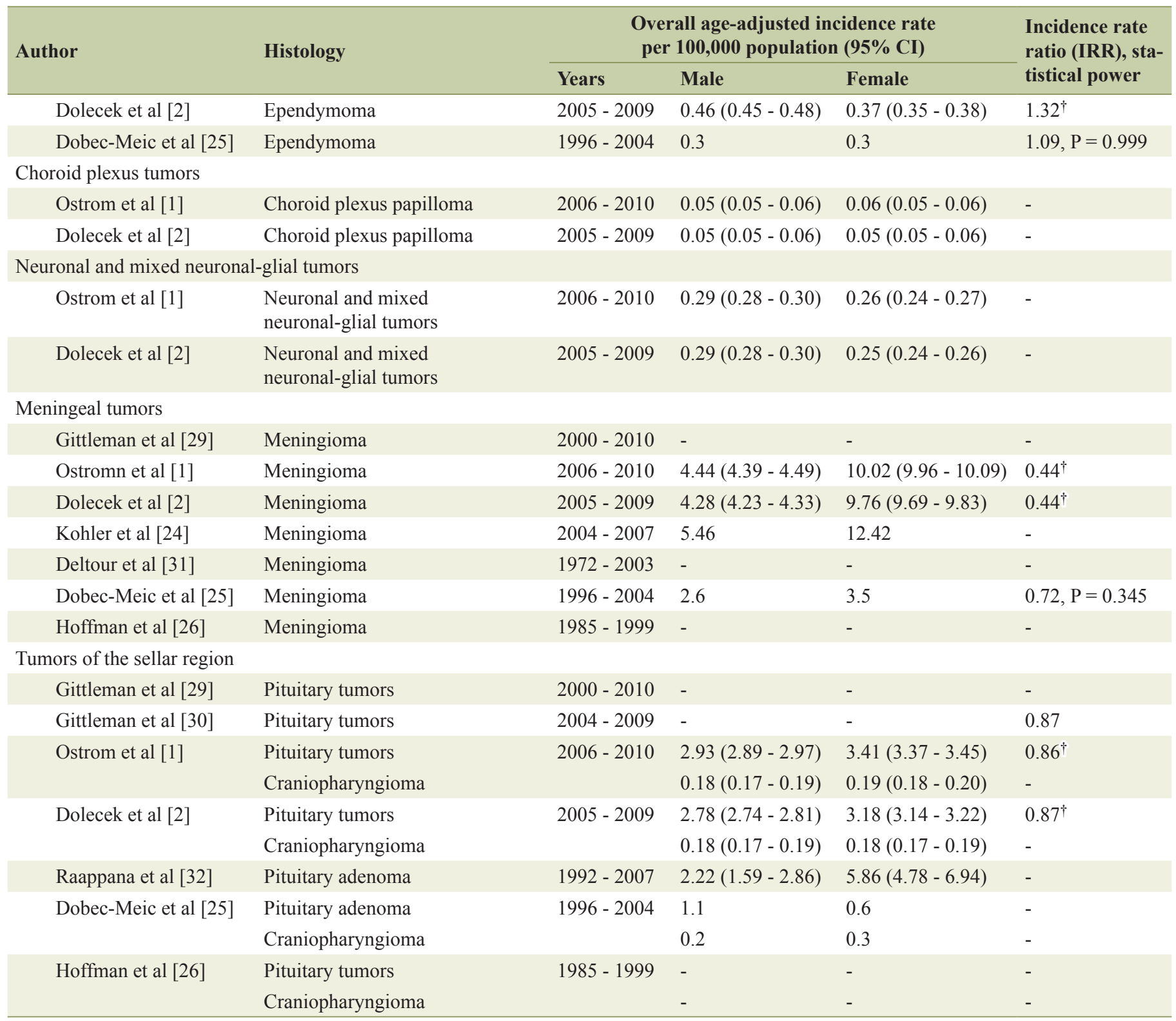

${ }^{\dagger}$ Statistically significant, $\mathrm{P}<0.05$.

1996 and 2010. The two US studies based on CBTRUS registry data showed male to female IRR of 1.30 and 1.26 , respectively, both statistically significant.

In the studied data by Dobec-Meic et al (2006), no male had gotten the diagnosis of oligodendroglioma, thus the incidence rate (not age-adjusted) was 0 per 100,000. The female incidence rate was 0.4 per 100,000, which was a number based on three cases [15].

\section{Oligoastrocytic tumors}

Two studies reported incidence rate data on oligoastrocytic tumors, both based on US CBTRUS registry data. The ageadjusted incidence rate amongst these tumors was 0.24 per 100,000 in men and 0.17 to 0.18 per 100,000 in women. One study [1] showed a statistically significant male to female IRR of 1.41. However, the other US study [2] presented a non-significant male to female IRR of 1.37 .

\section{Ependymal tumors}

Three studies showed data on incidence rate of ependymal tumors; two from US CBTRUS registries and one from Croatia. The incidence rate ranged from 0.3 to 0.47 per 100,000 in men 
Table 3. International Classification of Diseases for Oncology (ICD-O) Codes Used

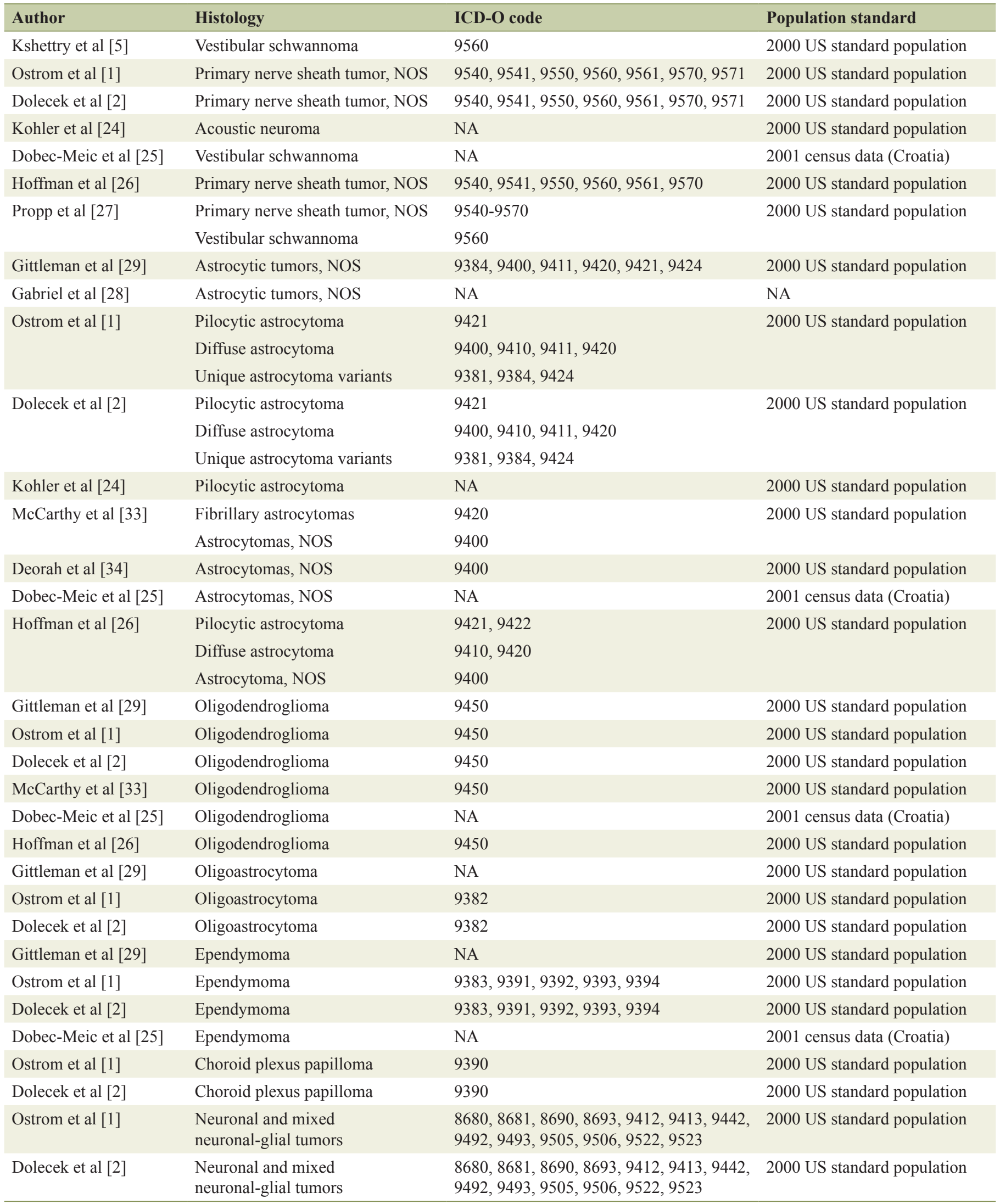


Table 3. International Classification of Diseases for Oncology (ICD-O) Codes Used - (continued)

\begin{tabular}{|c|c|c|c|}
\hline Author & Histology & ICD-O code & Population standard \\
\hline Gittleman et al [29] & Meningioma & NA & 2000 US standard population \\
\hline Ostrom et al [1] & Meningioma & $\begin{array}{l}9530,9531,9532,9533 \\
9534,9537,9538,9539\end{array}$ & 2000 US standard population \\
\hline Dolecek et al [2] & Meningioma & $\begin{array}{l}9530,9531,9532,9533 \\
9534,9537,9538,9539\end{array}$ & 2000 US standard population \\
\hline Kohler et al [24] & Meningioma & NA & 2000 US standard population \\
\hline Dobec-Meic et al [25] & Meningioma & NA & 2001 census data (Croatia) \\
\hline Hoffman et al [26] & Meningioma & $9530-9534,9537-9539$ & 2000 US standard population \\
\hline Gittleman et al [29] & Pituitary tumors & NA & 2000 US standard population \\
\hline Gittleman et al [30] & Pituitary tumors & $\begin{array}{l}8040,8140,8146,8246,8260,8270 \\
8271,8272,8280,8281,8290 \\
8300,8310,8323,9492,9582\end{array}$ & 2000 US standard population \\
\hline Ostrom et al [1] & Craniopharyngioma & $9350,9351,9352$ & \\
\hline \multirow[t]{2}{*}{ Dolecek et al [2] } & Pituitary tumors & $\begin{array}{l}8040,8140,8146,8246,8260,8270 \\
8271,8272,8280,8281,8290 \\
8300,8310,8323,9492,9582\end{array}$ & 2000 US standard population \\
\hline & Craniopharyngioma & $9350,9351,9352$ & \\
\hline Raappanas et al [32] & Pituitary adenoma & NA & WHO 2000 standard population \\
\hline \multirow[t]{2}{*}{ Dobec-Meic et al [25] } & Pituitary adenoma & NA & 2000 US standard population \\
\hline & Craniopharyngioma & NA & \\
\hline
\end{tabular}

and 0.3 to 0.37 in women between years 1996 and 2010. Both US studies had statistically significant male to female IRR of 1.31 and 1.32 , respectively.

\section{Choroid plexus tumors}

Only two studies analyzed choroid plexus tumors, both from US, based on CBTRUS data. Age-adjusted incidence rate was 0.05 per 100,000 in men and ranged from 0.05 to 0.06 per 100,000 in women between years 2005 and 2010. No male to female IRR was calculated in neither study.

\section{Neuronal and mixed neuronal-glial tumors}

Two studies presented data of all neuronal and mixed neuronal-glial tumors (ICD-O codes 8680, 8681, 8690, 8693, 9412, 9413, 9442, 9492, 9493, 9505, 9506, 9522 and 9523), thus also including the anaplastic ganglioglioma (WHO grade
III) together, yielding incidence rates of 0.29 per 100,000 in men and 0.25 to 0.26 per 100,000 in women between years 2005 and 2010.

\section{Meningeal tumors}

Four studies showed results of incidence rates in meningeal tumors, of which three were based on US CBTRUS data and one presented results on Croatian population. Incidence rates ranged from 2.6 to 5.46 per 100,000 in men and 3.5 to 12.42 per 100,000 in women between years 1996 and 2010. Two of these studies included all non-malignant meningiomas (ICDO codes 9530/0,1; 9531, 9532, 9533, 9534, 9537, 9538 and 9539), whereas two presented average annual age-adjusted incidence rates on meningiomas, NOS (no ICD-O histology codes specified). The Croatian study only included 40 meningioma diagnoses, thus those numbers should be interpreted by caution. The two large US studies both calculated statistically significant male to female IRR of 0.44 . 
Tumors of the sellar region

A total of four studies presented incidence rates of tumors of the sellar region, of which two were based on US population, one from Finland and one from Croatia. Three studies showed incidence rates of pituitary tumors (ICD-O codes 8040, 8140, $8146,8246,8260,8270,8271,8272,8280,8281,8290,8300$, $8310,8323,9492$ and 9582) and the Finnish study analyzed the average annual incidence rates of pituitary adenomas (ICD-O codes not specified). The incidence rates ranged from 1.1 to 2.93 per 100,000 in men and 0.6 to 5.86 per 100,000 in women. The US based studies showed male to female IRR of 0.86 and 0.87 , respectively, both statistically significant. Raappana et al showed female to male IRR of 2.5 and the Croatian study had a male to female IRR of 1.9 (not statistically significant). However, this study only included 11 cases of pituitary adenomas, thus those numbers should be interpreted carefully.

Three studies showed incidence data on craniopharyngiomas (not the Finnish study). The US studies defined the diagnosis by ICD-O codes 9350, 9351 and 9352, whereas the Croatian study did not specify ICD codes. Incidence rates ranged from 0.18 to 0.2 per 100,000 in men and 0.18 to 0.3 per 100,000 in women between years 1996 and 2010.

\section{Discussion}

The impact of sex differences in human disease is a wellknown yet often overlooked aspect. In this regard, cancer is no exception, where there are evident differences between men and women in terms of incidence and prognosis for different tumors.

In this review of reported incidence rates of low-grade primary tumors in adults, we have found no significant difference in overall incidence between men and women. Furthermore, we have found no significant time trend of age-adjusted incidence rate in neither male nor female patients. However, when taking only menigiomas into account, the age-adjusted incidence rates were higher in women and two of three studies with IRR calculations showed a statistically significant male to female IRR of 0.44 , meaning menigiomas are diagnosed about twice as often in females as in males. Likewise, the studies reporting incidence rate of pituitary tumors showed higher incidence in women than in men (IRR $0.4-0.87$ ).

This is a comprehensive review containing incidence data for men and women from different countries. To our knowledge, it is the first international comparison that has been conducted concerning possible gender differences in incidence rates of low-grade brain tumors. However, the interpretation of these results must be done carefully and no absolute conclusion can be made. One major issue with the present review regards the selection of studies that has been performed. The data search in this study was made in one electronic database only, PubMed, thus relevant articles might have been missed. Also the inclusions were made based on review aim rather than methodological quality. Furthermore, out of the 224 articles that were initially found, 210 were excluded for various reasons leaving only 14 papers available for analysis, which may lead to additional selection bias. One obvious selection regards the dominance of US population patients in the reviewed studies, thus the average annual age-adjusted incidence rate was based on the 2000 US standard population. Furthermore, in some of the studies of US population, there may be overlapping data. The Finnish study by Raappana et al (2010) used the WHO 2000 standard population, Dobec-Meic et al (2006) used 2001 Varazdin County census data in Croatia to make the estimations, and Deltour et al (2009) used national population registers in Sweden, Finland, Denmark and Norway to estimate the incidence rate. This may result in different incidence rates based on the calculation rather than on the absolute incidence rate. Also, similar tumor groupings, for example, primary nerve sheath tumors, NOS, had different ICD-O histology codes between studies, meaning that comparison within the tumor groupings must be made with caution. Some studies even did not state the ICD-O histology codes. Also, the number of inclusions, and thus the statistical power of different incidence rates between men and women varied throughout the studies. For example, the total number of included patients with a diagnosis of tumors of the cranial and paraspinal nerves in Dobec-Meic et al (2006) was 8, compared to the number of inclusions by Ostrom et al (2013) $(n=26,548$ cases $)$.

As the general incidence rate of low-grade brain tumors in men and women differs through time, a possible covariate could be that all different tumor groupings are not analyzed in the same time period. This may result in a false change in incidence rate within low-grade tumors over time. For example, meningiomas which have relatively high incidence rates in both men and women only have powerful data between years 2004 and 2010, probably influencing the increase in incidence rate in the later years in our analysis.

When analyzing the incidence of cancers affecting both men and women, the male to female incidence ratios often range from 1.5:1 to $3: 1$. Males have higher incidence rates for most cancers and usually also poorer overall survival [35-38]. This indicates that sex plays a major role in tumorigenesis. In malignant gliomas, the incidence has previously been reported to be higher in males [39]. Meningiomas, on the other hand, are reported to be much more likely to occur in women. Furthermore, in addition to the difference in incidence, female meningiomas are more commonly low grade, whereas the male menigiomas are more commonly high grade [39]. The reason behind this may be an effect of the different levels of sex steroids in men and women as meningiomas rarely develop in prepubertal children and menigiomas have been shown to express progesterone and estrogen receptors [40]. Also there have been reports of a higher risk of menigioma in women subjected to hormone replacement therapies [41]. Furthermore, there may be a protective effect of testosterone as men with prostate cancer undergoing androgen deprivation therapy have been shown to have an increased risk of meningioma growth [42].

As the results must be interpreted with caution, more large international studies are warranted and should be made in a standardized manner differing low-grade tumors from highgrade tumors according to the WHO 2007 brain tumor classification system. Also future studies should always state the ICD-O histology coding to ease future interpretations. 


\section{Conflicts of Interest}

None.

\section{References}

1. Ostrom QT, Gittleman H, Farah P, Ondracek A, Chen Y, Wolinsky Y, Stroup NE, et al. CBTRUS statistical report: Primary brain and central nervous system tumors diagnosed in the United States in 2006-2010. Neuro Oncol. 2013;1(Suppl 2):ii1-56.

2. Dolecek TA, Propp JM, Stroup NE, Kruchko C. CBTRUS statistical report: primary brain and central nervous system tumors diagnosed in the United States in 2005-2009. Neuro Oncol. 2012;14(Suppl 5):v1-49.

3. Lonn S, Klaeboe L, Hall P, Mathiesen T, Auvinen A, Christensen HC, Johansen C, et al. Incidence trends of adult primary intracerebral tumors in four Nordic countries. Int J Cancer. 2004;108(3):450-455.

4. Gal TJ, Shinn J, Huang B. Current epidemiology and management trends in acoustic neuroma. Otolaryngol Head Neck Surg. 2010;142(5):677-681.

5. Kshettry VR, Hsieh JK, Ostrom QT, Kruchko C, Barnholtz-Sloan JS. Incidence of vestibular schwannomas in the United States. J Neurooncol. 2015;124(2):223-228.

6. Larjavaara S, Feychting M, Sankila R, Johansen C, Klaeboe L, Schuz J, Auvinen A. Incidence trends of vestibular schwannomas in Denmark, Finland, Norway and Sweden in 1987-2007. Br J Cancer. 2011;105(7):1069-1075.

7. Zouaoui S, Darlix A, Rigau V, Mathieu-Daude H, Bauchet F, Bessaoud F, Fabbro-Peray P, et al. Descriptive epidemiology of 13,038 newly diagnosed and histologically confirmed meningiomas in France: 2006-2010. Neurochirurgie. 2015.

8. Tabernero MD, Espinosa AB, Maillo A, Rebelo O, Vera JF, Sayagues JM, Merino M, et al. Patient gender is associated with distinct patterns of chromosomal abnormalities and sex chromosome linked gene-expression profiles in meningiomas. Oncologist. 2007;12(10):1225-1236.

9. Practice, B. Overview of brain tumours. Available from: http://bestpractice.bmj.com/best-practice/monograph/262.html.

10. Louis DN, Ohgaki H, Wiestler OD, Cavenee WK, Burger PC, Jouvet A, Scheithauer BW, et al. The 2007 WHO classification of tumours of the central nervous system. Acta Neuropathol. 2007;114(2):97-109.

11. Organization, W.H. International classification of diseases. Available from: http:/www.who.int/classifications/ icd/en/.

12. Organization, W.H. International classification of diseases history.

13. Organization, W.H. International classification of disease for oncology.

14. Health, N.I.o., Systematic Nomenclature of Medicine.

15. States, C.B.T.R.o.t.U., CBTRUS.

16. Institute, N.C., The Surveillance, Epidemiology and End Results program.
17. Prevention, C.f.D.C.a., National Program of Cancer Registries.

18. Health, M.o., New Zealand Cancer Registry.

19. Socialstyrelsen, Swedish Cancer Registry.

20. Cancer-research, I.o.P.b., Cancer registry of Norway.

21. Gjerstorff ML. The Danish Cancer Registry. Scand J Public Health. 2011;39(7 Suppl):42-45.

22. Research, I.f.S.a.E.C., Finnish Cancer Registry.

23. Kleihues P, Burger PC, Scheithauer BW. The new WHO classification of brain tumours. Brain Pathol. 1993;3(3):255-268.

24. Kohler BA, Ward E, McCarthy BJ, Schymura MJ, Ries LA, Eheman C, Jemal A, et al. Annual report to the nation on the status of cancer, 1975-2007, featuring tumors of the brain and other nervous system. J Natl Cancer Inst. 2011;103(9):714-736.

25. Dobec-Meic B, Pikija S, Cvetko D, Trkulja V, Pazanin L, Kudelic N, Rotim K, et al. Intracranial tumors in adult population of the Varazdin County (Croatia) 1996-2004: a population-based retrospective incidence study. J Neurooncol. 2006;78(3):303-310.

26. Hoffman S, Propp JM, McCarthy BJ. Temporal trends in incidence of primary brain tumors in the United States, 1985-1999. Neuro Oncol. 2006;8(1):27-37.

27. Propp JM, McCarthy BJ, Davis FG, Preston-Martin S. Descriptive epidemiology of vestibular schwannomas. Neuro Oncol. 2006;8(1):1-11.

28. Gabriel A, Batey J, Capogreco J, Kimball D, Walters A, Tubbs RS, Loukas M. Adult brain cancer in the U.S. black population: a Surveillance, Epidemiology, and End Results (SEER) analysis of incidence, survival, and trends. Med Sci Monit. 2014;20:1510-1517.

29. Gittleman HR, Ostrom QT, Rouse CD, Dowling JA, de Blank PM, Kruchko CA, Elder JB, et al. Trends in central nervous system tumor incidence relative to other common cancers in adults, adolescents, and children in the United States, 2000 to 2010. Cancer. 2015;121(1):102-112.

30. Gittleman H, Ostrom QT, Farah PD, Ondracek A, Chen Y, Wolinsky Y, Kruchko C, et al. Descriptive epidemiology of pituitary tumors in the United States, 2004-2009. J Neurosurg. 2014;121(3):527-535.

31. Deltour I, Auvinen A, Feychting M, Johansen C, Klaeboe L, Sankila R, Schuz J. Mobile phone use and incidence of glioma in the Nordic countries 1979-2008: consistency check. Epidemiology. 2012;23(2):301-307.

32. Raappana A, Koivukangas J, Ebeling T, Pirila T. Incidence of pituitary adenomas in Northern Finland in 19922007. J Clin Endocrinol Metab. 2010;95(9):4268-4275.

33. McCarthy BJ, Propp JM, Davis FG, Burger PC. Time trends in oligodendroglial and astrocytic tumor incidence. Neuroepidemiology. 2008;30(1):34-44.

34. Deorah S, Lynch CF, Sibenaller ZA, Ryken TC. Trends in brain cancer incidence and survival in the United States: Surveillance, Epidemiology, and End Results Program, 1973 to 2001. Neurosurg Focus. 2006;20(4):E1.

35. Siegel R, DeSantis C, Virgo K, Stein K, Mariotto A, Smith T, Cooper D, et al. Cancer treatment and survivorship statistics, 2012. CA Cancer J Clin. 2012;62(4):220241. 
36. Molife R, Lorigan P, MacNeil S. Gender and survival in malignant tumours. Cancer Treat Rev. 2001;27(4):201209.

37. Ashley DJ. A male-female differential in tumour incidence. Br J Cancer. 1969;23(1):21-25.

38. Cook MB, McGlynn KA, Devesa SS, Freedman ND, Anderson WF. Sex disparities in cancer mortality and survival. Cancer Epidemiol Biomarkers Prev. 2011;20(8):16291637.

39. Sun T, Warrington NM, Rubin JB. Why does Jack, and not Jill, break his crown? Sex disparity in brain tumors. Biol Sex Differ. 2012;3:3.

40. Guevara P, Escobar-Arriaga E, Saavedra-Perez D, Mar-
tinez-Rumayor A, Flores-Estrada D, Rembao D, Calderon $\mathrm{A}$, et al. Angiogenesis and expression of estrogen and progesterone receptors as predictive factors for recurrence of meningioma. J Neurooncol. 2010;98(3):379-384.

41. Blitshteyn S, Crook JE, Jaeckle KA. Is there an association between meningioma and hormone replacement therapy? J Clin Oncol. 2008;26(2):279-282.

42. Li Q, Coulson H, Klaassen Z, Sharma S, Ramalingam P, Moses KA, Terris MK. Emerging association between androgen deprivation therapy and male meningioma: significant expression of luteinizing hormone-releasing hormone receptor in male meningioma. Prostate Cancer Prostatic Dis. 2013;16(4):387-390. 